\title{
Photodegradation of Some Quinolones Used as Antimicrobial Therapeutics
}

\author{
Eva-Maria Tiefenbacher", Ekkehard Haen*, Bernhard Przybilla ${ }^{\ddagger}$, and Hermann Kurz \\ Received March 5, 1992, from the 'Walther-Straub Institute of Pharmacology and Toxicology, Ludwig-Maximilians-University, \\ Nussbaumstr. 26, D-80336 Munich, Germany, and ‡Department of Dermatology, Ludwig-Maximilians-University, \\ Frauenlobstr. 9-11, D-80337 Munich, Germany. Accepted for publication October 25, $1993^{\circ}$.
}

Abstract $\square$ The photostability of the fluoroquinolones ciprofloxacin (CPX), ofloxacin (OFX), and fleroxacin (FLX) toward ultraviolet irradiation (UVA) and room light was investigated in dilute aqueous solutions. A series of photoproducts was observed by high-performance liquid chromatography (HPLC) for all three drugs. As little as $1 \mathrm{~h}$ of exposure to room light was enough for the formation of detectable amounts of CPX photoproducts. The major CPX photoproduct was characterized as a dimer by liquid secondary ion mass spectrometry, but its structure was not determined. Since irradiation of CPX results (as cited in ref/ 11 ) in a loss of antibacterial activity and since all substances, parent drugs as well as their photoproducts, are potential candidates for undesired drug effects, quinolone drugs should be strictly protected from all light during storage and administration.

\section{Introduction}

The 6-fluoroquinolones ciprofloxacin, ofloxacin, and fleroxacin represent a class of synthetic antimicrobial agents with a broad range of activity against Gram-negative and Gram-positive organisms (Figure 1). The drugs are used for the treatment of severe infections of different organs. ${ }^{1}$ Various side effects have been observed due to therapy with these compounds such as effects on the central nervous system and the gastrointestinal tract as well as photosensitivity reactions of the skin. ${ }^{2}$ Fluoroquinolones absorb radiation energy in the ultraviolet range of the electromagnetic spectrum ${ }^{3}$ (Figure 2). Some of these substances have been found to exert phototoxic or photoallergic effects in vivo or in vitro. ${ }^{4-6}$ Exact mechanisms of these reactions are unknown so far. They could be induced by the substances themselves or by derivatives formed as a consequence of UV irradiation. ${ }^{7-10}$

Ferguson et al. ${ }^{11}$ observed a loss of antibacterial activity of ciprofloxacin after UV exposure, suggesting photodegradation of the compound. The photodegradation itself has not yet been documented, as well as no information has been so far provided on the nature of the photoproducts. For some fluoroquinolones, however, metabolites have been identified with reduced antibacterial activity ${ }^{12-14}$ (Figure 3).

We assessed the formation of photoproducts after exposure of the fluoroquinolones ciprofloxacin, ofloxacin, and fleroxacin to UVA or natural/artificial light (room light). CPX metabolites were available for matters of comparison.

\section{Materials and Methods}

Chemicals. Ciprofloxacin and four of its metabolites were kindly supplied by Bayer AG (Leverkusen/FRG). Specifications were as follows: CPX (Bay O $9867 \cdot \mathrm{HCl} \cdot \mathrm{H}_{2} \mathrm{O}, 98.3 \%$ purity); metabolite M1 (Bay $\mathrm{R} 3964 \cdot \mathrm{HCl}, 96 \%$ purity); metabolite $\mathrm{M} 2$ (Bay S $9435 \cdot \mathrm{NH}_{3}, 90.3 \%$ purity); metabolite M3 (Bay Q 3542, 99\% purity); metabolite M4 (Bay P 9357, $99 \%$ purity). For some experiments, ciprofloxacin was used as Ciprobay infusion concentrate (Bayer AG/FRG). OFX was kindly supplied by Hoechst AG (Frankfurt/FRG), FLX by Hoffmann-La Roche AG (Grenzach-Whylen/FRG). All reagents were of analytical grade. Meth-

- Abstract published in Advance ACS Abstracts, January 15, 1994.<smiles>[X][C@H](C)O[C]</smiles><smiles>[X][R]F</smiles>

Flgure 1-Molecular structures of ciprofloxacin (CPX), ofloxacin (OFX), and fleroxacin (FLX).
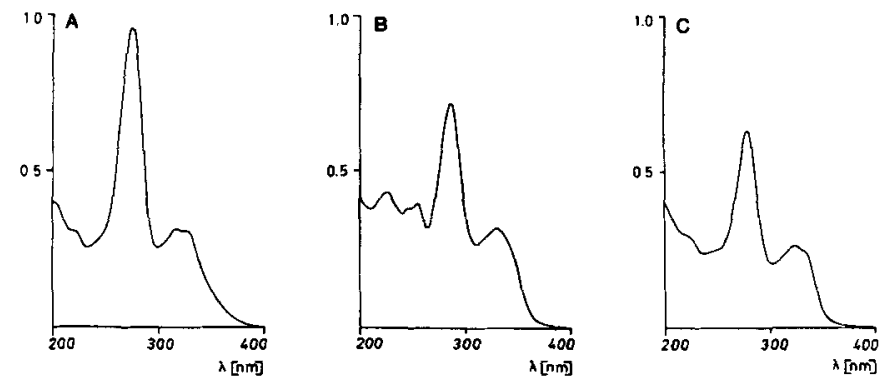

Figure 2-UV absorption spectra of ciprofloxacin (A), ofloxacin (B), and fleroxacin (C) (maxima: ciprofloxacin, $275 \mathrm{~nm}$; ofloxacin, $286 \mathrm{~nm}$; fleroxacin, $278 \mathrm{~nm}$; drug concentration: $10^{-5} \mathrm{~mol} / \mathrm{L}$, UV/vis recording spectrophotometer: UV-265 FW, Shimadzu/Japan).

anol, tetrahydrofuran, disodium hydrogen phosphate, and citric acid were obtained from Merck (Darmstadt/FRG), tetrabutylammonium hydrogen sulfate from Fluka Chemie AG (Buchs/Switzerland). Water was demineralized, double distilled, and filtered on a Milli-Q filter system (Millipore Corp., Bedfort, MA).

Sample Preparation and Irradiation-CPX, OFX, FLX, and the CPX metabolites were diluted at a concentration of $10^{-5} \mathrm{~mol} / \mathrm{L}$ in doubledistilled water with addition of $1.0 \mathrm{~mL}$ of $0.01 \mathrm{~N} \mathrm{NaOH}$ per $100.0 \mathrm{~mL}$ $\left(\mathrm{pH}_{\mathrm{cpz}}=5.4, \mathrm{pH}_{\mathrm{ofx}}=6.3, \mathrm{pH}_{\mathrm{fx}}=6.3\right)$. UVA irradiation of the solutions was performed with a high-intensity UVA source emitting in the range of $320-460 \mathrm{~nm}$ with a maximum at about $375 \mathrm{~nm}$ (UVASUN 5000 , Mutzhas, Munich/FRG). Irradiance at a distance of $40 \mathrm{~cm}$ was $37 \mathrm{~mW} /$ $\mathrm{cm}^{2}$ (UVA dose, $100 \mathrm{~J} / \mathrm{cm}^{2}$; irradiation time, $33 \mathrm{~min}$ ). During this procedure temperature increased from $20^{\circ} \mathrm{C}$ to $37^{\circ} \mathrm{C}$. Samples covered by aluminium foil were used as controls. Further experiments were performed at $4^{\circ} \mathrm{C}$ and at constant $20^{\circ} \mathrm{C}$ (in water bath). After irradiation all samples were immediately protected from light by aluminium foil. UVA dose was measured by an integrating instrument (Centra-UV dosimeter, Osram, Munich/FRG).

Exposure to natural/artificial light (room light) was studied with Ciprobay infusion concentrate. The concentrate was diluted to $10^{-5}$ $\mathrm{mol} / \mathrm{L}$ in double-distilled water, filled in transparent glass bottles, and 


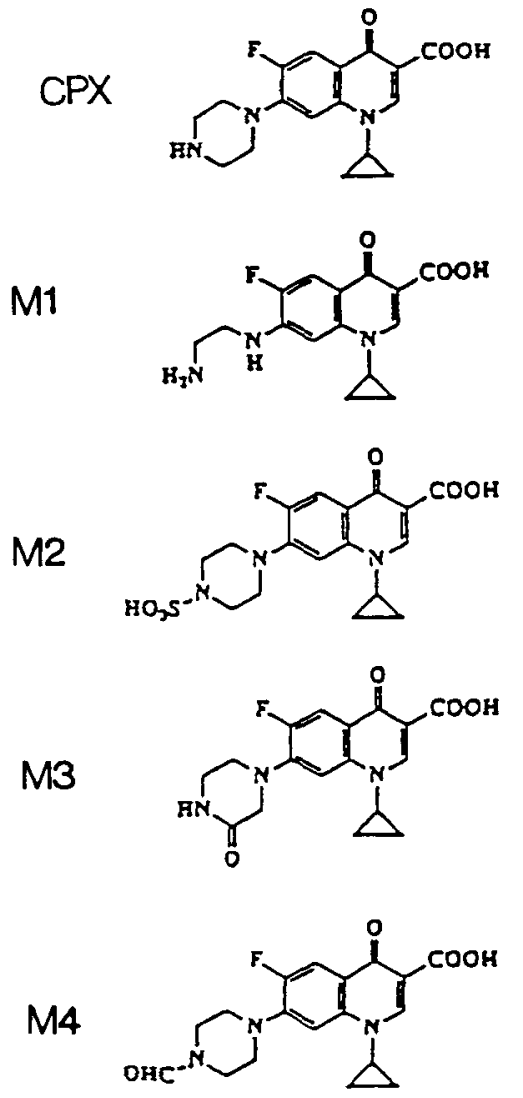

Figure 3-Molecular structures of ciprofloxacin (CPX) and its metabolites M1-M4. M1, desethylenciprofloxacin; M2, sulfociprofloxacin; M3, oxociprofloxacin; M4, formylciprofloxacin.

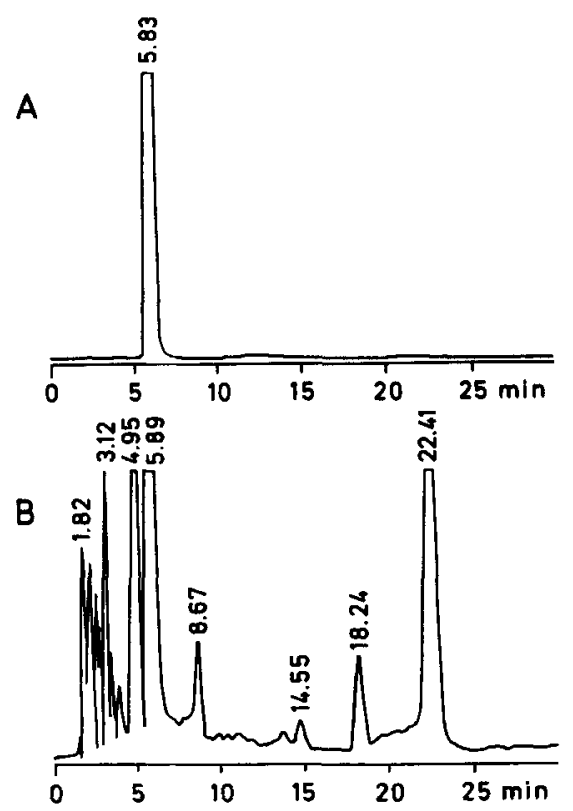

Flgure 4-HPLC chromatogram of ciprofloxacin $\left(10^{-5} \mathrm{~mol} / \mathrm{L}\right)$ without (A) and after $(B)$ irradiation with $100 \mathrm{~J} / \mathrm{cm}^{2}$ UVA (absorbance at $275 \mathrm{~nm}$; mobile phase: phosphate buffer pH 3.0/THF/methanol (79.2:0.8:20.0 vol $\%), 2.0 \mathrm{~mL} / \mathrm{L} \mathrm{H}_{3} \mathrm{PO}_{4}, 2.0 \mathrm{~g} / \mathrm{L}$ TBA; column: BDS-Hypersil $\mathrm{C}_{18}, 5 \mu \mathrm{m}, 150$ $\times 4.6 \mathrm{~mm}$; flow: $1.0 \mathrm{~mL} / \mathrm{min}$; injection volume: $20 \mu \mathrm{L}$ ).

placed on a desk in front of a window for 10-h exposure to normal day light. Irradiation was continued during the night with artificial light (desk lamp, 75-W bulb, distance: $40 \mathrm{~cm}$ ). After 1, 2, 3, 4, 12, 24, 48, and $96 \mathrm{~h}$, samples were drawn and protected by aluminum foil until chromatography was performed.
Table 1-HPLC Retention Times of Ciprofloxacin, Its Metabolites M1-M4, and Its Photoproducts Puv Formed under Irradiation with $100 \mathrm{~J} / \mathrm{cm}^{2}$ UVA $(\mathrm{min} ; \bar{x} \pm \mathrm{SD}, n=5)$

\begin{tabular}{lll}
\hline Ciprofloxacin & Metabolites & Photoproducts \\
\hline & & Puv1: $1.82 \pm 0.2$ \\
& & Puv2: $2.11 \pm 0.2$ \\
& Puv3: $2.74 \pm 0.3$ \\
& & Puv4: $3.12 \pm 0.4$ \\
& & Puv5: $3.70 \pm 0.4$ \\
& M2: $4.01 \pm 0.2$ & Puv6: $3.86 \pm 0.2$ \\
& M1: $4.98 \pm 0.4$ & Puv7: $4.95 \pm 0.2$ \\
& M3: $6.67 \pm 0.5$ & Puv8: $5.89 \pm 0.3$ \\
& & Puv9: $8.67 \pm 0.4$ \\
& M4: $18.59 \pm 0.9$ & Puv10: $14.55 \pm 0.7$ \\
& & Puv11: $18.24 \pm 0.3$ \\
& &
\end{tabular}

High-Performance Liquid Chromatography (HPLC)-Analytical Chromatography-Maxima of UV absorption of CPX, OFX, and FLX were determined by an UV-visible recording spectrophotometer (UV$265 \mathrm{FW}$, Shimadzu/Japan, Figure 2). The drug concentration was $10^{-5}$ $\mathrm{mol} / \mathrm{L}$. Analytical HPLC analysis was performed by a modification of the procedure published by Scholl et al. ${ }^{15}$ Reversed-phase columns (BDSHypersil $\mathrm{C}_{18}, 5 \mu \mathrm{m}, 150 \times 4.6 \mathrm{~mm}$, ODS-Hypersil, $3 \mu \mathrm{m}, 125 \times 4.6 \mathrm{~mm}$, Bischof $\mathrm{GmbH}$, Leonberg/FRG) were connected with a constant flow pump (Model $300 \mathrm{~B}$, Gynkotek GmbH, Munich/FRG) and a variablewavelength spectrophotometer (Model SP-6V, Gynkotek). The mobile phase consisted of $0.67 \mathrm{~mol} / \mathrm{L}$ phosphate buffer ( $\mathrm{pH} 3.0$ )/methanol/ tetrahydrofuran $(79.2 \mathrm{vol} \% / 20.0 \mathrm{vol} \% / 0.8 \mathrm{vol} \%)$ with addition of 2.0 $\mathrm{g} / \mathrm{L}$ tetrabutylammonium hydrogen sulfate (TBA) and $2.0 \mathrm{ml} / \mathrm{L}$ phosphoric acid $(85 \%)$. The solution was passed over a membrane filter (pore size $0.45 \mu \mathrm{m}$ ) and sonificated for $60 \mathrm{~s}$ with a sonorex RK 100 ultrasonic homogenizer (Brandelin GmbH, Berlin/FRG) before chromatography. The flow was $1.0 \mathrm{~mL} / \mathrm{min}$, the injection volume $20 \mu \mathrm{L}$. The substances were detected at 275 (CPX), 286 (OFX), and $278 \mathrm{~nm}$ (FLX).

Preparative Chromatography-The chromatograph consisted of the following modules: a pump (Model $300 \mathrm{~B}$, Gynkotek GmbH, Munich/ FRG), an automatic sampler (Model GINA, Gynkotek GmbH), a preparative reversed-phase column (HIPAK $\mathrm{C}_{18}, 5 \mu \mathrm{m}, 250 \times 20 \mathrm{~mm}$, Bischof $\mathrm{GmbH}$, Leonberg/FRG), and a variable-wavelength detector (Model SP-6V, Gynkotek GmbH). The solvent system was a mixture of $59.2 \%$ double-distilled water, $40.0 \%$ methanol, and $0.8 \%$ tetrahydrofuran with addition of $50.0 \mathrm{~mL} / \mathrm{L}$ formic acid. The flow was adjusted to $9 \mathrm{~mL} / \mathrm{min}$. The injection volume was $100 \mu \mathrm{L}$, and the separation was monitored at $275 \mathrm{~nm}$.

Mass Spectrometry-The liquid secundary ion mass spectrometry (LSI-MS) was performed with a HSQ 30 mass spectrometer (Finnigan MAT, Bremen/FRG). The probe temperature was $20^{\circ} \mathrm{C}$, the ionization energy $70 \mathrm{eV}$. A cesium ion beam was used (acceleration voltage, $7 \mathrm{kV}$; $100-\mu \mathrm{A}$ ion beam). The matrix consisted of glycerol, Spectrometry was performed in W. Schäfer's laboratory (Max-Planck-Institute, Martinsried/FRG).

\section{Results}

UVA - Nonirradiated CPX was detected at a retention time of $5.83 \pm 0.1 \mathrm{~min}(\bar{x} \pm \mathrm{SD}, n=5)$. CPX metabolites M1-M4 were found between $4.01 \pm 0.2$ and $18.59 \pm 0.9 \min (\bar{x} \pm \mathrm{SD}, n$ $=5$, Table 1). After UVA irradiation, the chromatograms of CPX solutions exhibited at least 12 well-defined peaks ( $\mathrm{P}_{U V} 1-$

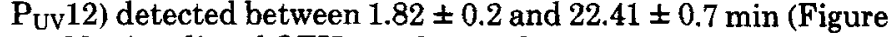
4). Nonirradiated OFX was detected at $6.38 \pm 0.2 \mathrm{~min}(\bar{x} \pm \mathrm{SD}$, $n=3$ ). Following UVA irradiation, there were at least seven degradation products with retention times between $2.88 \pm 0.3$ and $15.2 \pm 0.5 \mathrm{~min}$ (Figure 5). Nonirradiated FLX was detected at $4.94 \pm 0.3 \mathrm{~min}(\bar{x} \pm \mathrm{SD}, n=3)$. After UVA exposure at least eight peaks occurred at $5.09 \pm 0.2$ to $13.41 \pm 0.3 \mathrm{~min}$ (Figure 6).

Identical chromatograms were obtained after irradiations performed at constant temperatures of $4^{\circ} \mathrm{C}$ or $20^{\circ} \mathrm{C}$. No 
Table 2-Concentrations of Clprofloxacin Photoproducts $P_{L}$ Formed under Irradlation with Natural/Artificial Light (Peak Area in \% of Peak Area of Parent Drug, $R_{f}$ : Retention Time)

\begin{tabular}{llllllllll}
\hline & & \multicolumn{8}{c}{ Exposure Time } \\
\cline { 2 - 9 } $\mathrm{P}_{\mathrm{L}}$ & $R_{f}(\min )$ & $1 \mathrm{~h}$ & $2 \mathrm{~h}$ & $3 \mathrm{~h}$ & $4 \mathrm{~h}$ & $12 \mathrm{~h}$ & $24 \mathrm{~h}$ & $48 \mathrm{~h}$ & $96 \mathrm{~h}$ \\
\hline $\mathrm{P}_{\mathrm{L} 1:}$ & 1.93 & & 0.1 & 0.1 & 0.2 & 0.2 & 0.2 & 0.3 & 0.3 \\
$\mathrm{P}_{\mathrm{L} 2:}$ & 2.36 & & 0.1 & 0.1 & 0.1 & 0.1 & 0.2 & 0.2 & 0.6 \\
$\mathrm{P}_{\mathrm{L}} 3:$ & 3.22 & & 0.1 & 0.1 & 0.2 & 0.2 & 0.4 & 0.4 & 0.8 \\
$\mathrm{P}_{\mathrm{L}} 4:$ & 3.97 & 0.1 & 0.1 & 0.1 & 0.1 & 0.1 & 0.2 & 0.1 & 0.4 \\
$\mathrm{P}_{\mathrm{L}} 5:$ & 5.03 & 0.2 & 0.4 & 0.5 & 0.7 & 1.2 & 1.5 & 2.5 & 6.3 \\
$\mathrm{P}_{\mathrm{L}} 7:$ & 8.97 & & & & & 0.1 & 0.1 & 0.2 & 0.4 \\
& Total & 0.3 & 0.8 & 0.9 & 1.3 & 1.9 & 2.6 & 3.7 & 8.8 \\
& & & & & & & & & \\
\hline
\end{tabular}
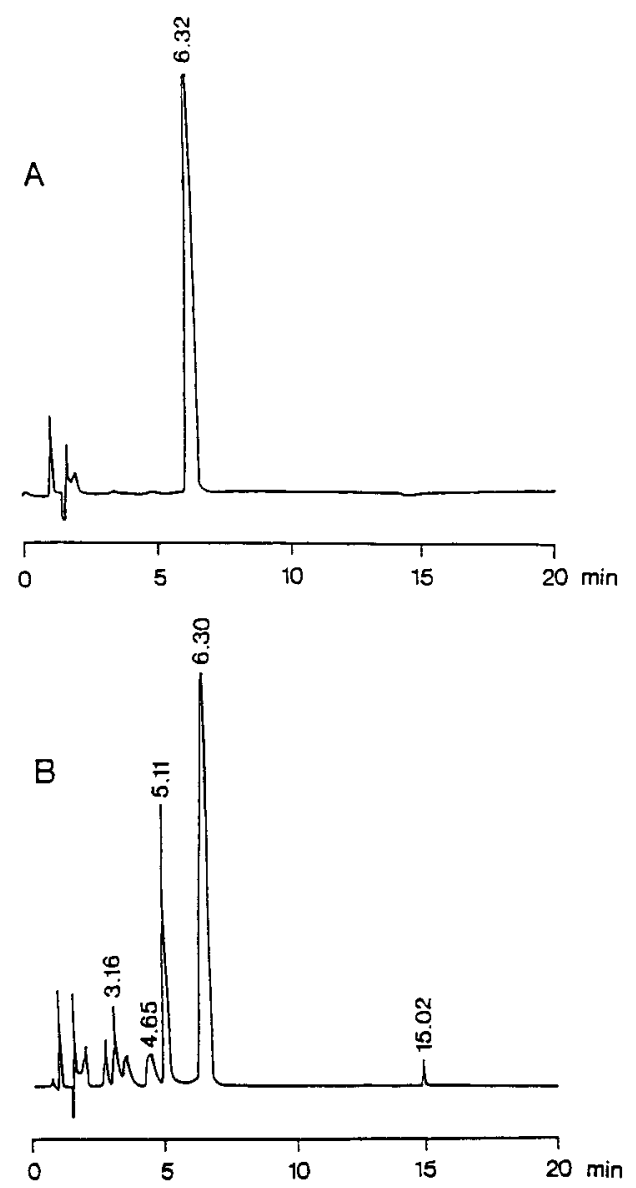

Figure 5-HPLC chromatogram of ofloxacin $\left(10^{-5} \mathrm{~mol} / \mathrm{L}\right)$ without (A) and after (B) irradiation with $100 \mathrm{~J} / \mathrm{cm}^{2}$ UVA (absorbance at $286 \mathrm{~nm}$, mobile phase: phosphate buffer $\mathrm{pH} 3.0 / \mathrm{THF} /$ methanol $(79.2: 0.8: 20.0 \mathrm{vol} \%)$, $2.0 \mathrm{~mL} / \mathrm{L} \mathrm{H}_{3} \mathrm{PO}_{4}, 2.0 \mathrm{~g} / \mathrm{L}$ TBA; column: ODS-Hypersil $\mathrm{C}_{18}, 3 \mu \mathrm{m}, 125 \times$ $4.6 \mathrm{~mm}$; flow: $1.0 \mathrm{~mL} / \mathrm{min}$; injection volume: $20 \mu \mathrm{L}$ ).

degradation of the substances was observed in control samples (irradiated under cover with aluminum foil).

Natural/Artificial Light-Under irradiation of CPX solutions with natural/artificial ambient light the peak of the parent substance $\left(\mathbf{P}_{\mathrm{L}} 6\right)$ decreased continuously. Concomitantly, new peaks $\left(\mathrm{P}_{\mathrm{L}} 1-\mathrm{P}_{\mathrm{L}} 5, \mathrm{P}_{\mathrm{L}} 7\right)$ appeared in increasing concentrations with retention times between $1.93 \pm 0.1$ and $8.97 \pm 0.2 \min (\bar{x} \pm S D$, $n=5$, Figure 7, Table 2). The most prominent peak was detected at $5.03 \pm 0.1 \mathrm{~min}$, similar to the retention time of $P_{U V} 7$ at 4.95 $\pm 0.2 \mathrm{~min}$ (Table 1 ).

Chromatographic Purity of CPX-Concentrations of CPX photoproducts were calculated from peak areas. The sum of peak areas formed in Ciprobay infusion concentrate after UVA

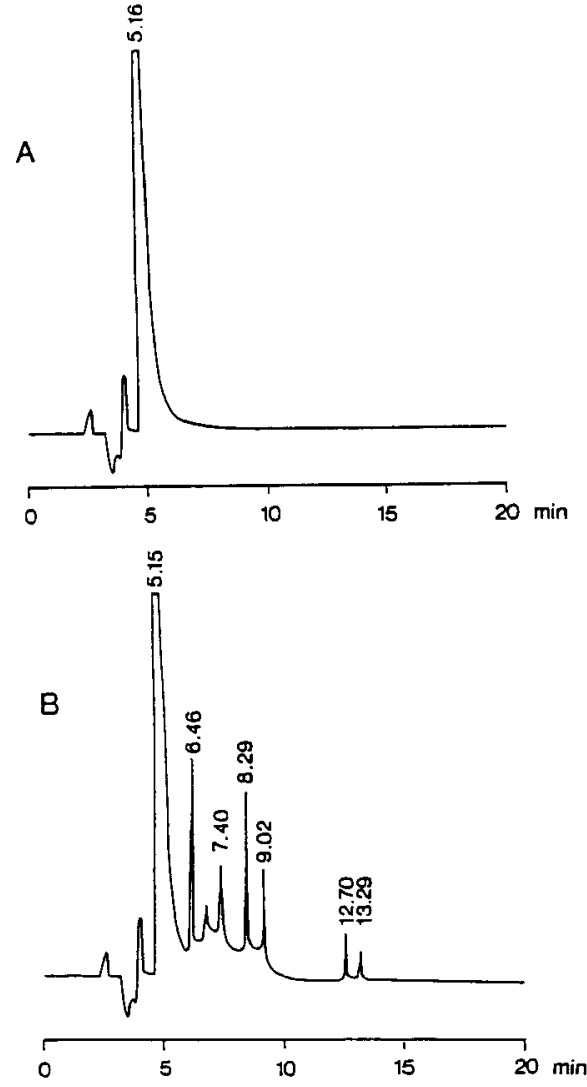

Flgure 6-HPLC chromatogram of fleroxacin $\left(10^{-5} \mathrm{~mol} / \mathrm{L}\right)$ without (A) and after (B) irradiation with $100 \mathrm{~J} / \mathrm{cm}^{2}$ UVA (absorbance at $278 \mathrm{~nm}$; mobile phase: phosphate buffer $\mathrm{pH} 3.0 / \mathrm{THF} /$ methanol $(79.2: 0.8: 20.0$ vol \%), $2.0 \mathrm{~g} / \mathrm{L} \mathrm{H}_{3} \mathrm{PO}_{4}, 2.0 \mathrm{~mL} / \mathrm{L}$ TBA; column: ODS-Hypersil $\mathrm{C}_{18}, 3 \mu \mathrm{m}, 125 \times$ $4.6 \mathrm{~mm}$; flow: $1.0 \mathrm{~mL} / \mathrm{min}$; injection volume: $20 \mu \mathrm{L}$ ).

exposure with $100 \mathrm{~J} / \mathrm{cm}^{2}$ UVA amounted to $17.0 \pm 1.8 \%$ of the parent drug, after 96-h exposure to room light to $8.8 \pm 1.4 \%$ (Table 2).

LSI Mass Spectra of CPX Photoproducts PUv7 and $P_{U v} 8$ - The LSI mass spectra of CPX and photoproduct $P_{U V} 8$ with their typical fragmentation pathway are given in Figure 8. The characteristic peaks in the MS of CPX are in complete agreement with those of $\mathrm{P}_{\mathrm{Uv}} 8: \mathrm{m} / z 332(\mathrm{M}+\mathrm{H}), 290(\mathrm{M}-$ $\left.\mathrm{C}_{2} \mathrm{H}_{4} \mathrm{~N}\right), 246\left(\mathrm{M}-\mathrm{CO}_{2}-\mathrm{C}_{2} \mathrm{H}_{4} \mathrm{~N}\right)$, and $57\left(\mathrm{C}_{3} \mathrm{H}_{6} \mathrm{~N}\right)$. The LSI-MS of CPX photoproduct $\mathrm{P}_{U V} 7$ is demonstrated in Figure 9. The characteristic peaks are displayed at $m / z 703(\mathbf{M}+\mathrm{K}), 683$ $\left(\mathrm{M} \cdot \mathrm{H}_{2} \mathrm{O}\right)$, and $665(\mathrm{M}-\mathrm{M})$.

\section{Discussion and Conclusions}

All quinolones investigated degraded under exposure to UVA. Ciprofloxacin exposure to natural/artificial ambient light which always occurs when the drug is handled also leads to the formation of numerous photoproducts. These degradations were temperature independent, which is strong evidence that they are actually caused by irradiation.

CPX photoproduct $\mathrm{P}_{\mathrm{UV}} 8$ is detected in the HPLC chromatogramm at the same retention time as nonirradiated ciprofloxacin, suggesting their structural identity. This is confirmed by mass spectrometry of the compounds: both spectra exhibit exactly the same fragmentation pathway. Consequently " $\mathrm{P}_{U \mathrm{UV}} 8$ " does not represent a light-induced degradation product but parent ciprofloxacin which has not yet been decomposed under UVA influence.

The HPLC retention times of CPX photoproducts $P_{U V} 7$ and metabolite M1 are also very similar. The published MS spectrum 

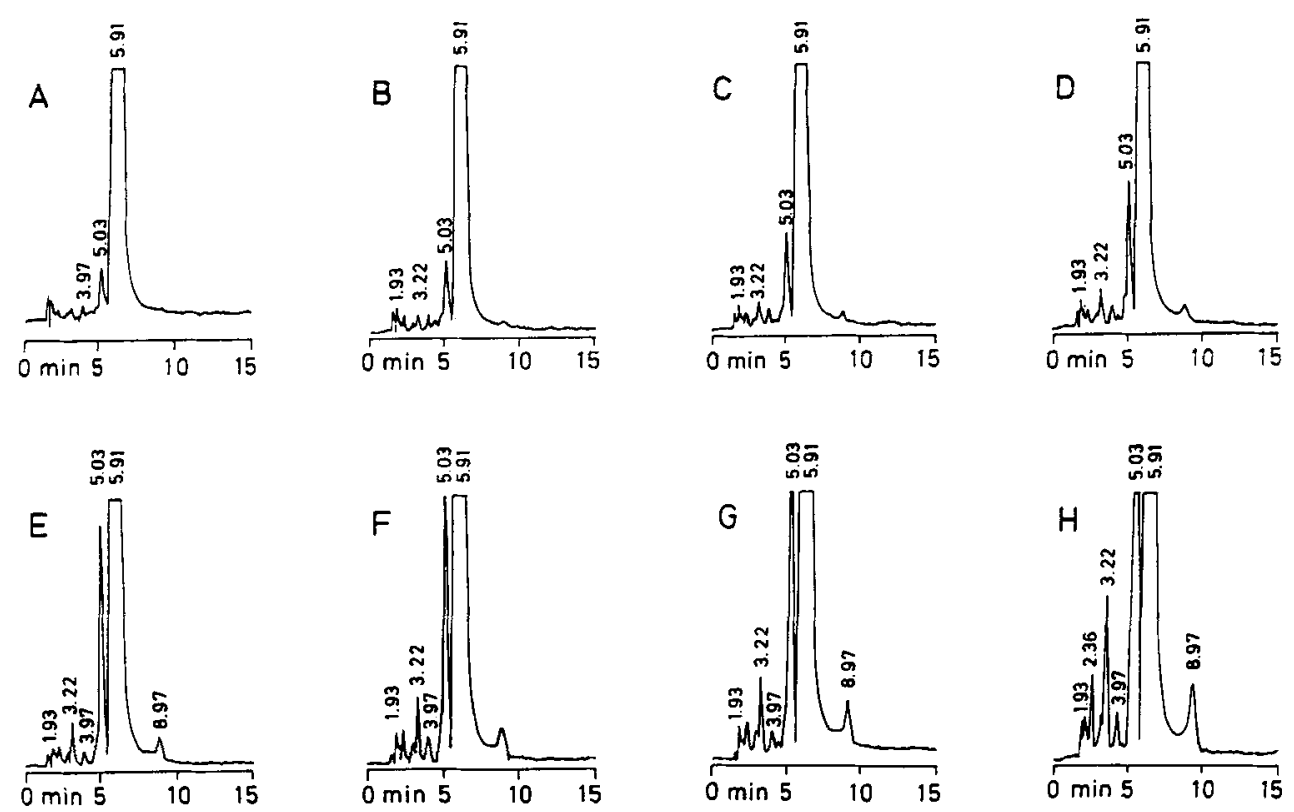

Flgure 7-HPLC chromatograms of ciprofloxacin under irradiation with natural/artificial light (room light) after $1 \mathrm{~h} \mathrm{(A),} 2 \mathrm{~h}$ (B), $3 \mathrm{~h}$ (C), $4 \mathrm{~h}$ (D), $12 \mathrm{~h}$ $(E), 24 h(F), 48 h(G)$, and $96 h(H)$ (nonirradiated ciprofloxacin, Figure 4).
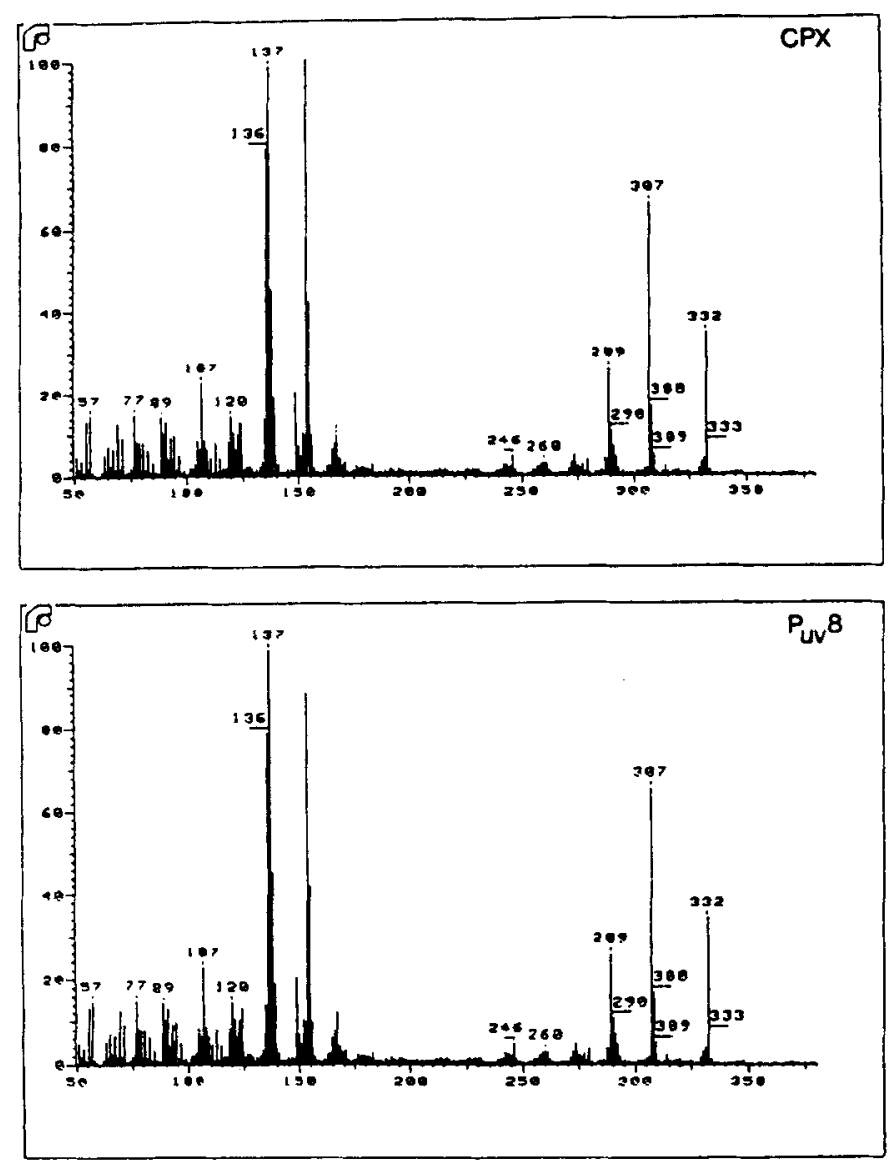

Figure 8-LSI-MS of ciprofloxacin (CPX) and CPX photoproduct Puv8. of $\mathrm{M} 1,{ }^{12}$ however, shows marked differences to the spectrum of $P_{U V} 7$ obtained in this study. In the MS spectrum of $P_{U V}{ }^{7}$, the characteristic ions are displayed at very high molecular weights, suggesting they might result from an UVA-induced CPX dimerization. Indeed, such a reaction could be expected from photochemical aspect: after UVA absorption the electronically excited states-likely in form of free radicals--become stabilized by bond reorganization of two radicals leading to CPX dimers.

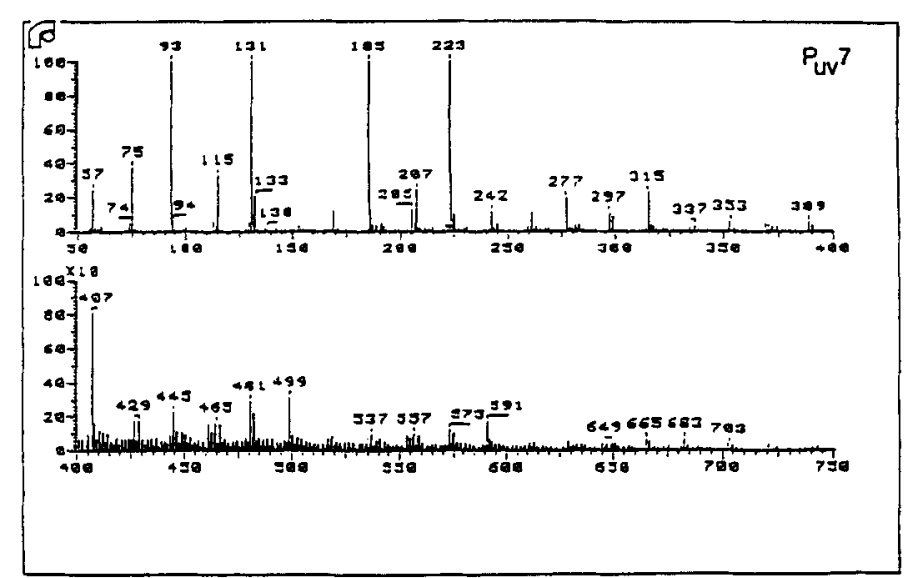

Figure 9-LSI-MS of CPX photoproduct Puv7.

Whether this hypothesis is correct will be shown by nuclear magnetic resonance spectrometry which is currently under investigation in our laboratory.

A reduction of antibacterial activity of ciprofloxacin has been reported after UVA exposure. Ferguson et al. ${ }^{11}$ suggested this to be the result of photodegradation of the substance. The results of this study demonstrate a considerable decrease of the concentration of ciprofloxacin under UVA exposure. Furthermore, a reduced antimicrobial activity has been reported for the metabolites of ciprofloxacin, ${ }^{16}$ suggesting that the photoproducts, too, will exhibit less antibacterial activity than the parent substance. Both mechanisms support the hypothesis that photodegradation of ciprofloxacin is responsible for the loss of antibacterial activity following UVA irradiation.

The extent of quinolone degradation depends on radiation dose. Photoproducts formed in ciprofloxacin infusion concentrate after exposure to $100 \mathrm{~J} / \mathrm{cm}^{2}$ UVA amount to $17.0 \pm 1.8 \%$ of the parent drug. After $4 \mathrm{~h}$ of exposure to room light, $1.3 \pm$ $0.4 \%$ and, after $96 \mathrm{~h}, 8.8 \pm 1.4 \%$ of the parent drug are degraded, numerous new substances have been formed (Table 2).

Photoproducts formed outside the organism under natural light conditions may be not only relevant to the loss of antibacterial activity, but also to the occurrence of side effects, ${ }^{17-19}$ phototoxic as well as others. Further work is necessary to 
evaluate the toxic potential of the fluoroquinolone photoproducts. To avoid progressive photodegradation, quinolones should be protected from natural and artificial light. For example they should be stored in amber glass bottles. Such precautions are easy to perform. They will minimize the loss of therapeutic activity as well as potentially increase the tolerance of the drugs, thereby optimizing the therapeutic potential of these valuable antibacterial agents.

\section{References and Notes}

1. Hooper, D. C.; Wolfson, J.S. Antimicrob. Agents Chemother. 1985, $28,716-721$.

2. Christ, W.; Lehnert, T.; Ulbrich, B. Rev. Infect. Dis. 1988, 10 (Suppl. 1), 141-146.

3. Haen, E.; Przybilla, B. Münch. Med. Wschr. 1988, 130, 23-29.

4. Przybilla, B.; Georgii, A.; Bergner, T.; Ring, J. Dermatologica 1990, $181,98-103$

5. Christ, W.; Schmidt, V. Fortschr. Antimikrob. Antineoplast. Chemother. 1984, 173, 795-804.

6. Baran, R.; Brun, P. Dermatologica 1986, 173, 185-188.

7. Kochevar, I. E.; Morison, W. L.; Lamm, J. L.; McAuliffe, D. J.; Western, A.; Hood, A. F. Arch. Dermatol. 1986, 122, 1283-1287.

8. Kochevar, I. E. J. Invest. Dermatol. 1981, 76, 59-64.

9. Castell, J. V.; Gomez, L. J.; Miranda, M. A.; Morera, I. M. Photochem. Photobiol. 1987, 46, 991-996.
10. Gasparro, F. P. Photodermatology 1985, 2, 151-157.

11. Ferguson, J.; Phillips, G.; McEwan, J.; Moreland, T.; Johnson, B. E. Br. J. Dermatol. 1988, 4, 119.

12. Gau, W.; Kurz, J.; Petersen, U.; Ploschke, H. J.; Wuensche, C. Arzneim. Forsch./Drug Res. 1986, 36, 1545-1549.

13. Georgopoulos, A.; Czejka, M. J.; Starzengruber, N. Int. J. Exp. Clin. Chemother. 1989, 2, 141-146.

14. Borner, K. J. Clin. Chem. Biochem. 1986, 24, 325-331.

15. Scholl, H.; Schmidt, K.; Weber, B. J. Chromatogr. 1987, 416, 321325.

16. Borner, K.; Lode, H. Infection 1986, 14 (Suppl. 1), 141-146.

17. De Mol, N. J.; Beijersbergen van Henegouwen, G. M. J.Photochem. Photobiol. 1981, 33, 815-819.

18. Schoonderwoerd, S. A.; Beijersbergen, van Henegouwen, G. M. J.; Luijendijk, J. J. Photochem. Photobiol. 1988, 48, 621-627.

19. Schoonderwoerd, S. A.; Beijersbergen van Henegouwen, G. M. J.; Van Belkum, S. Photochem. Photobiol. 1989, 50, 659-664.

\section{Acknowledgments}

The authors wish to express their deep gratitude to Prof. Dr. W. Schäfer (Max-Planck-Institute, Martinsried/FRG) for his generous and cooperative support. LSI mass spectra were performed in his laboratory. He also provided excellent assistance with their interpretation. This study was supported by a grant from the Deutsche Forschungsgemeinschaft (DFG No. Br 147/56-2) and by a grant from the Dr. RobertPfleger-Stiftung, Bamberg/FRG. E. Tiefenbacher is enrolled in a Ph.D. program; the results of this paper are part of her thesis. 